\title{
Type 2 segmental glomangioma - Case report*
}

\author{
Camila Raposo Cabral ${ }^{1}$ \\ Julliene Lika Matsumoto ${ }^{1}$ \\ A na Carolina Franco Tebet ${ }^{1}$
}

\author{
Jayme de Oliveira Filho ${ }^{1}$ \\ Stela Cignachi ${ }^{1}$ \\ Kássila da Rosa N asser ${ }^{1}$
}

DOI: http:/ / dx.doi.org/ 10.1590/ abd1806-4841.20152483

\begin{abstract}
Glomus tumors originate from modified perivascular muscle cells. The most common form is the solitary one. The multiple form may be associated with dominant genetic inheritance. We report a case of a patient with hemangiomatous lesions on the calcaneus and wrist since birth. In 6 years, there was progression of lesions throughout the body. Multiple glomangiomas are asymptomatic and more common in childhood. They can be confused with other vascular malformations. Histopathological diagnosis is essential. The case shows a type 2 segmental manifestation that can be explained by genetic mutation leading to the loss of heterozygosity. As the child grows, the lesions may disseminate due to mutation in distant parts of the skin. Literature shows few re ports. The treatment is conservative.
\end{abstract}

Keywords: Classification; Congenital abnormalities; Glomus tumor; International classification of diseases; Vascular malformations

\section{INTRODUCTION}

Glomus tumors originate from modified perivascular muscle cells, called glomic cells. These are located in arteriovenous anastomoses, responsible for thermoregulation control. Usually they are benign tumors which involve mainly the skin, besides compromising soft tissues and other organs. ${ }^{1}$

There are two forms of gl omus tumors: the solitary one, the most common (90\%), and a multiplevariant, whose incidence is more observed during infancy and may beassociated or not with genetic inheritance. The multiple variant is divided into plaque and nodular forms.

Histologically, glomus tumors are composed of glomic cells, blood vessels and smooth muscle cells. According to its predominance, the following forms occur: (1) Glomangioma - predominance of blood vessels; (2) Solid - predominance of glomic cells; (3) Glomangiomioma - predominance of smooth muscle.
In some autosomal dominant skin diseases, segmental forms may manifest cutaneous mosaicism. Two types of segmental arrangements can be described: (1) Type 1 - characterized by the presence of lesions with similar severity degree and reflecting the heterozygosity of the mutation; (2) Type 2 - originated by the loss of heterozygosity with aggressive involvement of skin and disseminated lesions. ${ }^{2,3}$

\section{CASE REPORT}

Male patient, 22 years old, with presence of macules of angiomatous aspect on the calcaneus and right wrist since birth (Figure 1). Lesions grew in size during infancy and became nodular, although without localized pain or other symptoms.

In the last six years there was dissemination of lesions to lower limbs, arms, back and abdomen (Figures 2 to 5). Lesions arenodular, violaceous, well-delimited, of fibroelastic consistency and painless. Bleeding

\footnotetext{
Received on 25.01.2013

Approved by theAdvisory Board and accepted for publication on 06.03.2014

* Work performed at Universidade de Santo A maro (Unisa) - Santo A maro (SP), Brazil.

Financial Support: None.

Conflict of Interest: None.

1 Universidade de Santo A maro (Unisa) - Santo A maro (SP), Brazil.
}

(C2015 by A nais Brasileiros de Dermatologia 


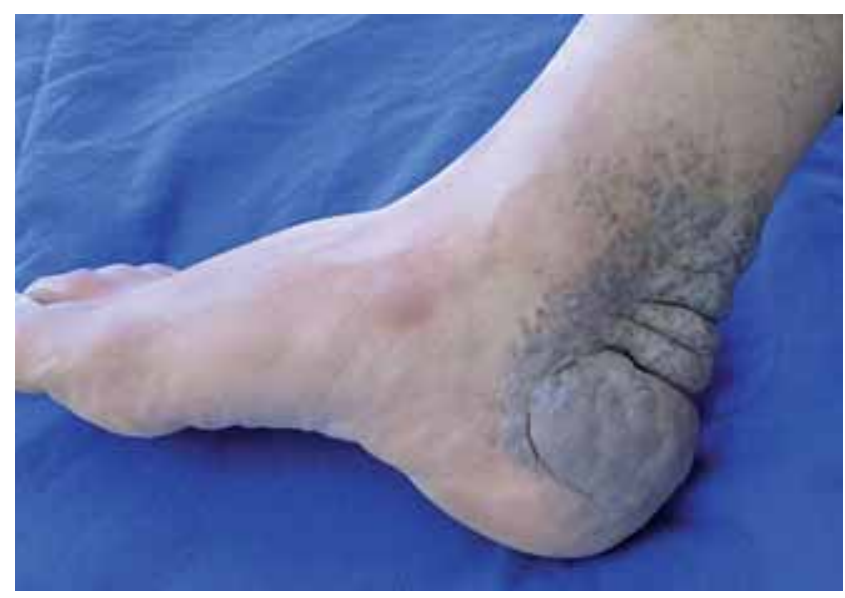

Figure 1: Right foot cal caneus. Involvement of whole right calcaneous by varicose lesions

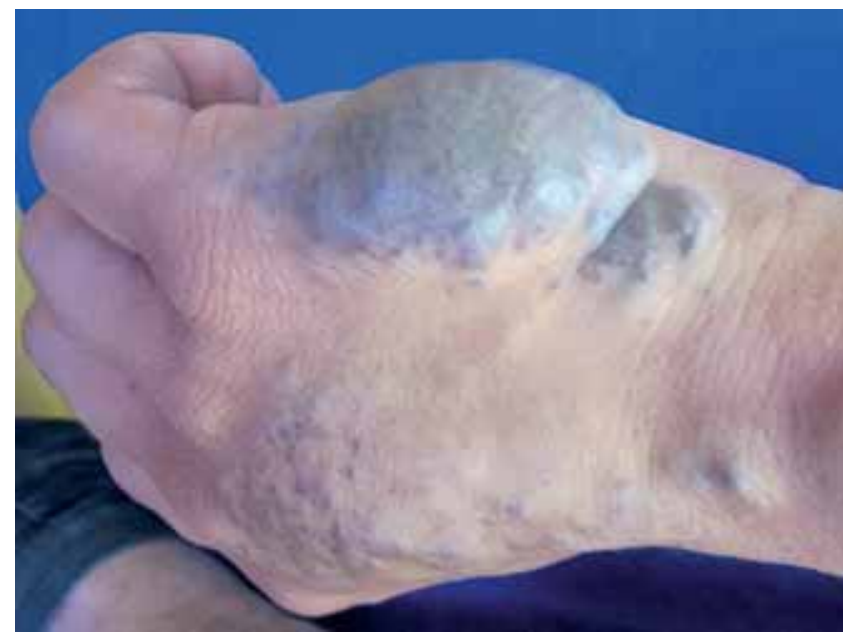

Figure 2: Right hand. Purplish nodular lesions on the wrist and back of right hand

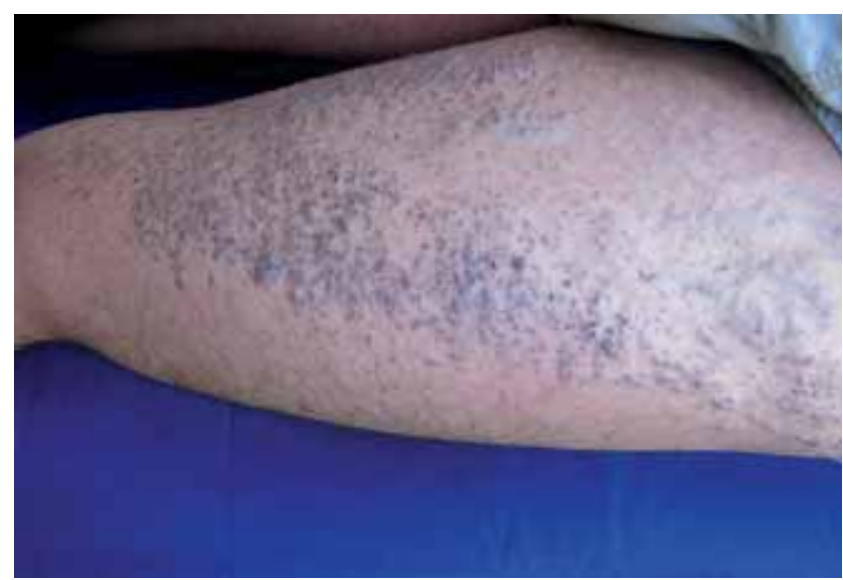

Figure 3: Lower left limb. Varicose lesions involving left thigh

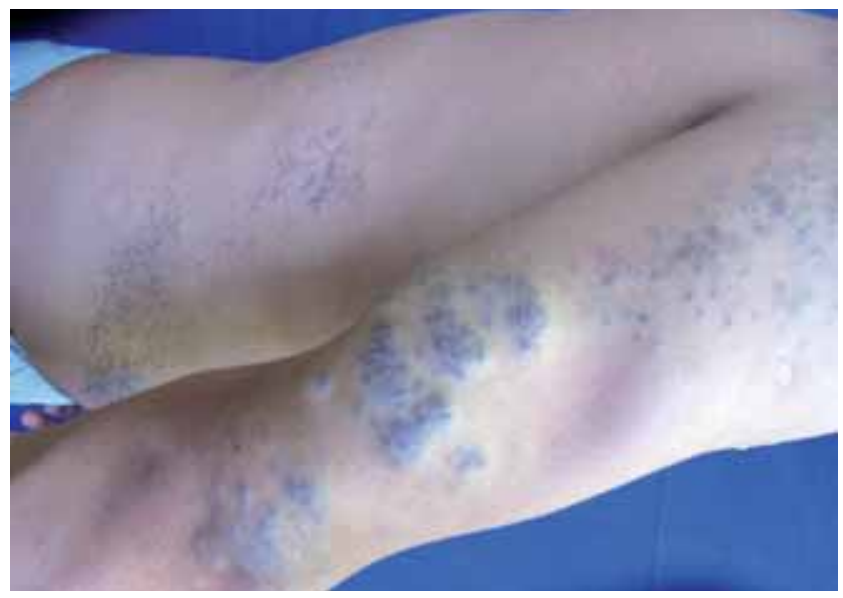

Figure 4: Right hemibody. Varicose lesions all over the right upper limb

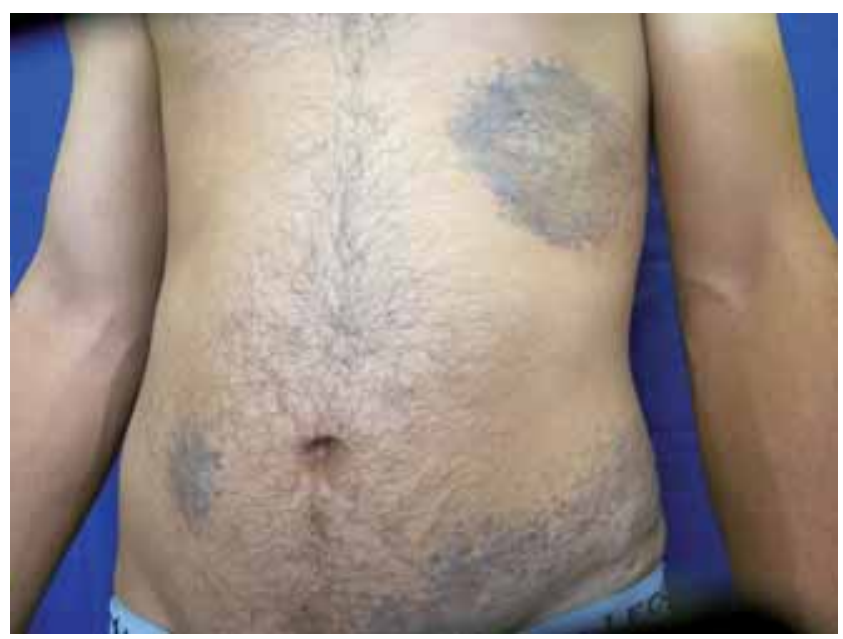

Figure 5: A bdomen and trunk. Later dissemination of lesions to abdomen and thorax

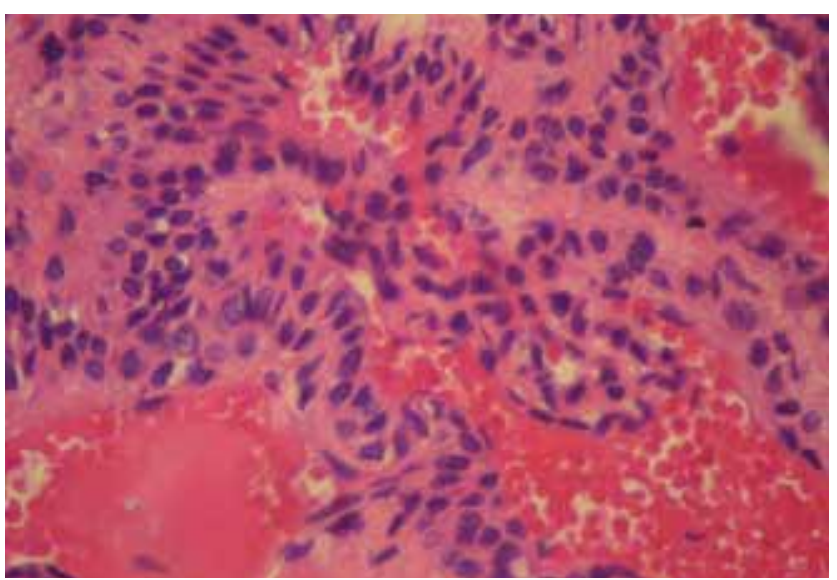

Figure 6: Histopathological examination. Perivascular infiltrate of glomic cells (H.E. objective 40x) 
episodes from small traumas have occurred, but there was no blood loss in the intestinal tract or in other systems. Patient denied presence of similar lesions in family members.

Histopathological examination revealed the presence of a poorly-delimited benign neoplasm in the deep dermis, characterized by ectatic and irregular vascular channels, with typical internal endothelial lining, surrounded by glomic cells. A bsence of atypia (Figure 6).

Laboratory tests presented hemoglobin, bleeding time, coagulation, platelet count and fecal occult blood within normal range.

\section{DISAUSSION}

The term "glomangioma" is still used abundantly but currently it is more appropriate to use "glomuvenous malformation", for it corresponds to the presence of vascular malformation caused by glomulin mutation. ${ }^{4}$

Glomus tumors are benign vascular lesions which are usually solitary and painful, and the most common form is subungual. In contrast, glomangiomas or gl omuvenous malformations, as a general rule, are present since infancy, may also involve systemic organs and are usually asymptomatic. Glomangiomas represent a small portion of glomus tumors. ${ }^{5}$

Glomuvenous malformations may be acquired by autosomal dominant inheritance, with incomplete penetrance and variable expressivity. The involved gene was located in chromosome 1p21-22. ${ }^{6}$

Some patients with multiple glomus tumors may present dissemination of lesions throughout their lives, in sites different from the initial lesions. Haple and Konig recently classified this change into two types, according to autosomal dominant alterations. Type 1 defines the presence of less severe lesions, or underlying loss of heterozygosity (new mutation which makes another normal allele inactive). Type 2 represents loss of heterozygosity during embryogenesis and leads to diffuse and severe development of glomus tumors. This alteration may occur in other types of cutaneous disorders, the most frequent being superficial actinic porokeratosis (Chart 1). 2,6

The combination of cutaneous involvement since birth, as well as development of new lesions suggests type 2 segmental manifestation. This can
Chart 1: Type 2 segmental manifestation of autosome dominant skin diseases

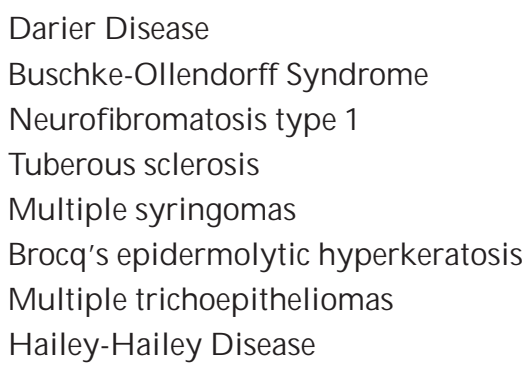

Source: Parsons ME et al. ${ }^{5}$

be explained by the genetic mutation which leads to loss of heterozygosity at the beginning of embryological formation. The presence of post-zygotic mutation in the embryonary period implies in total loss of glomuline function (molecule involved in the differentiation of smooth muscle) and leads to the formation of glomangiomas. Upon growing up, the individual may suffer dissemination of lesions, due to this mutation. ${ }^{3}$ In this case, the patient presented lesions on the limbs from birth, with dissemination to distant sites during puberty.

Familial cases were reported with dominant transmission and incomplete penetrance. The first case was described in 1967, by Berger and Hundeiker. In 2000, Peña-Penabad et al reported two cases of familial multiple glomangiomas, but the lesions had not been present from birth. 3,7,8 There have been less than 15 cases of congenital multiple glomus tumors, with type 2 segmental manifestations, reported to date. ${ }^{9} \mathrm{M}$ unoz et al found only 8 cases similar to those reported in the literature, in 2001. In all cases, the patients presented lesions with unilateral distribution which disseminated later. ${ }^{10}$

Clinically, the glomangioma may be mistaken for other venous malformations. The diagnosis may be reveal ed through histopathological examination by the presence of solid aggregates of glomic cells surrounding vessels.

The treatment proposed in these cases aims to merely alleviate symptoms. Surgical excision presents a recurrence rate of about $10 \%$. Other alternatives include sclerotherapy and ablative lasers. ${ }^{10} \square$ 


\section{REFERENCES}

1. Chatterjee JS, Youssef AH, Brown RM, Nishikawa H. Congenital nodular multiple glomangioma: a case report. J Clin Pathol. 2005;58:102-3.

2. Happle R, König A. Type 2 Segmental Manifestation for Multiple Glomus Tumors: A Review and Reclassification of 5 Case Reports. Dermatology. 1999;198:270-2.

3. Peña-Penabad C, García-Silva J, del Pozo J, Yebra-Pimentel MT, Fonseca E, Cuevas J, et al. Two cases of segmental multiple glomangiomas in a family: type 1 or type 2 segmental manifestation? Dermatology. 2000;201:65-7.

4. Solovan C, Chiticariu E, Beinsan D, Zurac S, Baderca F. Multiple disseminated glomuvenous malformations: do we know enough? Rom J Morphol Embryol. 2012;53:1077-80.

5. Parsons ME, Russo G, Fucich L, Millikan LE, Kim R. Multiple glomus tumors. Int J Dermatol. 1997;36:894-900.

6. Allombert-Blaise CJ, Batard ML, Ségard M, Martin de Lassalle $E$, Brevière GM, Piette F. Type 2 Segmental Manifestation of Congenital Multiple Glomangiomas. Dermatology. 2003;206:321-5.

7. Chatterjee JS, Youssef AH, Brown RM, Nishikawa H. Congenital nodular multiple glomangioma: a case report. J Clin Pathol. 2005;58:102-3.

8. Schiefer TK, Parker WL, Anakwenze OA, Amadio PC, Inwards CY, Spinner RJ. Extradigital Glomus Tumors: A 20-Year Experience. Mayo Clin Proc. 2006:81:1337-44.

9. Hoekzema R, Zonneveld IM, van der Wal AC. Type 2 segmental glomangiomas. Dermatol Online J. 2010;16:8.

10. Munoz C, Bobadilla F, Fuenzalida H, Goldner R, Sina B. Congenital glomangioma of the breast: type 2 segmental manifestation. Int J Dermatol. 2011;50:346-9.
M AILING ADDRESS:

Camila Raposo Cabral

Rua Professor Enéas de Siqueira N eto, 340

04829-300 - São Paulo - SP

Brazil

E-mail: camcabral@yahoo.com.br

How to cite this article: Cabral CR , Oliveira Filho J, Matsumoto JL, Cignachi S, Tebet ACF, Nasser KR. Type 2 segmental glomangioma: case report. . An Bras Dermatol. 2015;90 (3 Suppl 1):S97-100 